Hydrol. Earth Syst. Sci., 18, 1199-1212, 2014

www.hydrol-earth-syst-sci.net/18/1199/2014/

doi:10.5194/hess-18-1199-2014

(c) Author(s) 2014. CC Attribution 3.0 License.

\title{
A physically based approach for the estimation of root-zone soil moisture from surface measurements
}

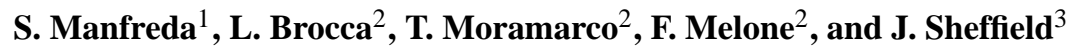 \\ ${ }^{1}$ School of Engineering, University of Basilicata, Potenza, Italy \\ ${ }^{2}$ Research Institute for Geo-Hydrological Protection (IRPI), National Research Council, Perugia, Italy \\ ${ }^{3}$ Department of Civil and Environmental Engineering, Princeton University, Princeton, NJ, USA
}

Correspondence to: S. Manfreda (salvatore.manfreda@unibas.it)

Received: 3 October 2012 - Published in Hydrol. Earth Syst. Sci. Discuss.: 20 December 2012

Revised: 27 January 2014 - Accepted: 10 February 2014 - Published: 28 March 2014

\begin{abstract}
In the present work, we developed a new formulation for the estimation of the soil moisture in the root zone based on the measured value of soil moisture at the surface. It was derived from a simplified soil water balance equation for semiarid environments that provides a closed form of the relationship between the root zone and the surface soil moisture with a limited number of physically consistent parameters. The method sheds lights on the mentioned relationship with possible applications in the use of satellite remote sensing retrievals of soil moisture. The proposed approach was used on soil moisture measurements taken from the African Monsoon Multidisciplinary Analysis (AMMA) and the Soil Climate Analysis Network (SCAN) databases. The AMMA network was designed with the aim to monitor three so-called mesoscale sites (super sites) located in Benin, Mali, and Niger using point measurements at different locations. Thereafter the new formulation was tested on three additional stations of SCAN in the state of New Mexico (US). Both databases are ideal for the application of such method, because they provide a good description of the soil moisture dynamics at the surface and the root zone using probes installed at different depths. The model was first applied with parameters assigned based on the physical characteristics of several sites. These results highlighted the potential of the methodology, providing a good description of the root-zone soil moisture. In the second part of the paper, the model performances were compared with those of the well-known exponential filter. Results show that this new approach provides good performances after calibration with a set of parameters consistent with the physical characteristics
\end{abstract}

of the investigated areas. The limited number of parameters and their physical interpretation makes the procedure appealing for further applications to other regions.

\section{Introduction}

Soil moisture information is critical for weather and climate prediction, hydrological forecast applications, and watershed management (e.g. Walker and Houser, 2004; Moran et al., 2004; Manfreda and Fiorentino, 2008; Seneviratne et al., 2010). However, in situ soil moisture observations are lacking over large spatial scales. A viable alternative strategy for obtaining spatial fields of soil moisture is from satellite remote sensing, which can provide continuous and largescale monitoring of the surface soil moisture state. These data represent an extraordinary source of information for hydrological applications; however they only provide information on near-surface soil moisture. For instance, soil moisture information derived from microwave sensors is directly related to the surface soil layer $(0.2-5 \mathrm{~cm})$ (Gao et al., 2006; Escorihuela et al., 2010), while the volume of soil considered of interest for monitoring and forecast applications is much deeper. The description of an analytical relationship between the soil moisture at the surface and in the lower soil layers has been a significant challenge (e.g. Ragab, 1995; Puma et al., 2005; Manfreda et al., 2007; Sabater et al., 2007) and warrants further study. This challenge was strongly emphasized in a recent review paper on the "state of the art in large-scale soil moisture monitoring" (Ochsner et al., 2013). 
An important contribution was given by Wagner et al. (1999), who suggested the use of an exponential filter of the form $\exp (-t / T)$, where $T$ is the characteristic length time or recession constant. This filter was used to convert the time series of surface measurements to a signal that is able to capture the dynamics of the lower soil layer. The great advantage of this filter lies in its simplicity due to the fact that it makes use of one parameter only. Moreover, the derived soil moisture index (SWI) relies only on the surface observation (remotely sensed data). Therefore, this approach, which from now on will be referred to as the SWI method, has been tested with both simulated and measured data, providing good results, and has been extensively used to improve the description of the root-zone soil moisture in rainfall-runoff applications (e.g. Manfreda et al., 2011; Brocca et al., 2010, 2012; Matgen et al., 2012a).

The growing interest in this approach makes it critical to provide a physical interpretation of the parameter $T$ that is influenced by a number of physical processes controlling soil moisture fluctuations. Several authors have tackled this problem (e.g. Ceballos et al., 2005; De Lange et al., 2008; Albergel et al., 2008). For instance, Ceballos et al. (2005) demonstrated that $T$ represents the parameter of the exponential autocorrelation function of soil moisture. For this reason, $T$ is influenced by all the physical processes affecting the temporal fluctuations of soil moisture (e.g. evapotranspiration, soil hydraulic properties, soil depth, number of soil layers, etc.). In this way, they demonstrated that the parameter $T$ is proportional to the ratio between the soil water content at field capacity and potential evapotranspiration. De Lange et al. (2008) tested the model for several soil textures using simulated data obtained with the finite-element HYDRUS-1D model. They demonstrated the strong influence that the soil parameters and the sampling periods have on $T$. According to these findings, the authors suggested that the SWI methodology should benefit from a soil texture differentiation. Another attempt to give a physical interpretation of the recession constant $(T)$ was carried out by Albergel et al. (2008), who investigated the correlation of the parameter, $T$, with soil properties and climate conditions over France. Unfortunately, they did not observe significant relationships between $T$ and the main soil properties (clay and sand fractions, bulk density and organic matter content).

An alternative and increasingly more useful approach is to assimilate satellite retrievals into land surface models (e.g. Reichle et al., 2002, 2004). Such an approach has benefitted from the progress made in recent years on assimilation methods and the availability of long-term records of retrievals from either microwave (e.g. Scipal et al., 2008) or thermal sensors (e.g. Crow et al., 2008), or both (e.g. Li et al., 2010).

The purpose of this paper is not to define an operational approach in place of assimilation systems, but to shed light on a phenomenon of general interest. The approach proposed here represents an attempt to describe analytically the relationship between the surface soil moisture and the root-zone soil moisture value using parameters that are related to the physical characteristics of the site under investigation. In this way, one may infer the soil moisture state below the surface using surface soil moisture data along with some physical characteristics of the site. The model presented herein represents an attempt to tackle this problem, providing a solution that may be considered reliable in dry areas. Our preliminary application has been carried out using soil moisture observations taken from the African Monsoon Multidisciplinary Analysis (AMMA) and the Soil Climate Analysis Network (SCAN) databases. These two networks represent valuable sources of soil moisture data measured at different depths that is shared via the web with the entire scientific community. In this way, these data have been involved in a significant number of calibration and validation activities that increases the interest and the information contents related to these networks. For the scope of this paper, we selected a number of stations with detailed information along the soil profile and also with some information on the soil texture. All stations have been selected in arid and semiarid environments. The results obtained are extremely encouraging and the methodology may represent a useful tool under some specific climatic conditions.

The paper is organized with a presentation of the new model in Sect. 2, where the SWI method is also described. Section 3 provides a description of the AMMA and SCAN databases and, finally, in Sect. 4, which precedes the conclusion, the model is applied for the AMMA and SCAN data and its performances are compared with those of the SWI method.

\section{Model description}

\subsection{Soil moisture analytical relationship (SMAR)}

Several hydrological models are based on a conceptual scheme with multiple layers in order to describe the soil moisture profile. Models that make use of remotely sensed data in assimilation frequently use such a representation with a surface layer of a few centimetres (e.g. Brocca et al., 2012). In the present work, the soil is assumed to be composed of two layers, one at the surface with a depth of a few centimetres (equivalent to the retrieval depth of the satellite sensor) and a second one below with a depth that may be assumed coincident with the rooting depth of vegetation (of the order of $60-150 \mathrm{~cm}$ ). From here on, we will refer to those as the first and second layer, respectively, and we will use a subscript "1" or "2" to distinguish between their variables and parameters.

The most relevant water mass exchange between the two layers is represented by infiltration. Other processes such as lateral flow and capillary rise are assumed negligible with respect to infiltration. The challenge is to define a soil water balance equation where the infiltration term is not expressed 
as a function of rainfall, but of the soil moisture content in the surface soil layer. This may allow the derivation of a function of the soil moisture in one layer as a function of the other one. The water flux from the top layer can be considered significant only when the soil moisture exceeds field capacity. Assuming that the soil moisture movement from the upper to the lower layer during a rainfall event can be modelled following the Green-Ampt approach (Green and Ampt, 1911), one can assume that all water in the first layer above field capacity will move into the lower layer within one day. This idea was inspired by the work of Laio (2006), who proposed a model for the description of the soil moisture profile.

Under such assumptions, the infiltration flux from the top layer to the lower occurs instantaneously and is described by

$$
\begin{aligned}
n_{1} \mathrm{Zr}_{1} y(t) & =n_{1} \mathrm{Zr}_{1} y\left[s_{1}(t), t\right] \\
& =n_{1} \mathrm{Zr}_{1} \begin{cases}\left(s_{1}(t)-s_{\mathrm{c} 1}\right), & s_{1}(t) \geq s_{\mathrm{c} 1} \\
0, & s_{1}(t)<s_{\mathrm{c} 1}\end{cases}
\end{aligned}
$$

where $y(t)[-]$ fraction of soil saturation infiltrating in the lower layer, $n_{1}[-]$ is the soil porosity of the first layer, $\mathrm{Zr}_{1}$ [L] is the depth of the first layer, $s_{1}\left(\theta_{1} / n_{1}\right)[-]$ is the relative saturation of the first layer (given by the ratio between the soil water content, $\theta_{1}$, and the porosity, $n_{1}$, of the first layer), and $s_{\mathrm{c} 1}[-]$ is the value of relative saturation at field capacity of the first layer of soil.

The above equation implies the assumption of an infinite permeability of the soil when the relative saturation reaches any value above field capacity. It is also necessary that the first layer not be infinitesimal, because this condition will lead to zero infiltration. Moreover, the model does not account for the saturation effect of the lower layer. It is necessary to note that, in order to avoid undesired underestimation of the infiltration, the surface soil moisture value should be referred to the first $5-10 \mathrm{~cm}$ of soil. A thickness of less than $5 \mathrm{~cm}$ may lead to numerical problems in this and other hydrological models. For this reason, several hydrological models that incorporate a surface layer in the soil description, assume a thickness of about $10 \mathrm{~cm}$ (e.g. Liang et al., 1994, 1996; Wood et al., 1997). Most satellite sensors cannot penetrate deeper than a few centimetres, but it is a reasonable assumption that these measures can be representative of the dynamics of a surface layer of approximately $5-10 \mathrm{~cm}$.

Following this reasoning, the soil water balance of the second and deeper soil layer is controlled by two main factors: infiltration and soil water losses. Given the infiltration equation, we can continue with a simplified approach assuming a linear soil water loss function that includes both evapotranspiration and percolation (e.g. Porporato et al., 2004; Rodriguez-Iturbe et al., 2006). Both these processes are negligible when the soil saturation is below the wilting point. For this reason we assumed that the soil losses decrease linearly from a maximum value under well-watered conditions to 0 at the wilting point.
Defining $x_{2}=\left(s_{2}-s_{\mathrm{w} 2}\right) /\left(1-s_{\mathrm{w} 2}\right)$ as the "effective" relative soil saturation of the second soil layer and $w_{0}=$ $\left(1-s_{\mathrm{w} 2}\right) n_{2} \mathrm{Zr}_{2}$ the soil water storage, the soil water balance can be described by the following expression:

$\left(1-s_{\mathrm{w} 2}\right) n_{2} \mathrm{Zr}_{2} \frac{\mathrm{d} x_{2}(t)}{\mathrm{d} t}=n_{1} \mathrm{Zr}_{1} y(t)-V_{2} x_{2}(t)$,

where $s_{2}[-]$ represents the relative saturation of the soil, $s_{\mathrm{w} 2}$ $[-]$ is the relative saturation at the wilting point, $n_{2}[-]$ is the soil porosity, $\mathrm{Zr}_{2}[\mathrm{~L}]$ is the soil depth, $V_{2}\left[\mathrm{LT}^{-1}\right]$ is the soil water loss coefficient accounting for both evapotranspiration and percolation losses, and $x_{2}[-]$ is the "effective" relative soil saturation of the second soil layer.

It should be noted that this equation does not account for the high non-linearity that characterizes the soil loss function for high values of soil moisture. This simplification, along with the fact that the infiltration does not account for the saturation effect, implies some limitations in the use of such an approach in humid environments. The model in fact was thought mainly for a semiarid environments with flat surfaces and neglecting the presence of phreatic surfaces, effects due to topographic convergence (e.g. subsurface flows), the presence of frozen soils, etc.

The equation above can be simplified using normalized coefficients $a$ and $b$ defined as

$a=\frac{V_{2}}{\left(1-s_{\mathrm{w} 2}\right) n_{2} \mathrm{Zr}_{2}}, \quad b=\frac{n_{1} \mathrm{Zr}_{1}}{\left(1-s_{\mathrm{w} 2}\right) n_{2} \mathrm{Zr}_{2}}$.

The value of these parameters can be related directly to the ratio of the depths of the two layers and the soil water loss coefficient. As a consequence, the soil water balance equation becomes

$\frac{\mathrm{d} x_{2}(t)}{\mathrm{d} t}=b y(t)-a x_{2}(t)$.

It is interesting to note that this equation represents a generalization that also includes the case proposed by Wagner et al. (1999). Assuming an initial condition for the relative saturation $x_{2}(t)$ equal to zero, one may derive an analytical solution to this linear differential equation:

$x_{2}(t)=\int_{0}^{t} b e^{a(w-t)} y(w) \mathrm{d} w$.

For practical applications, one may need the discrete form as well:

$x_{2}\left(t_{j}\right)=\sum_{i=0}^{j} b e^{a\left(t_{i}-t_{j}\right)} y\left(t_{i}\right) \Delta t$.

Expanding Eq. (6) and assuming $\Delta t=\left(t_{j}-t_{(j-1)}\right)$, one may derive the following expression for the soil moisture in the second layer based on the time series of surface soil moisture:

$x_{2}\left(t_{j}\right)=x_{2}\left(t_{j-1}\right) e^{-a\left(t_{j}-t_{j-1}\right)}+b y\left(t_{j}\right)\left(t_{j}-t_{j-1}\right)$, 
that may be rewritten as a function of $s_{2}$ as

$$
\begin{aligned}
s_{2}\left(t_{j}\right) & =s_{\mathrm{w} 2}+\left(s_{2}\left(t_{j-1}\right)-s_{\mathrm{w} 2}\right) e^{-a\left(t_{j}-t_{j-1}\right)} \\
& +\left(1-s_{\mathrm{w} 2}\right) b y\left(t_{j}\right)\left(t_{j}-t_{j-1}\right)
\end{aligned}
$$

The method proposed here represents a soil moisture analytical relationship (from now on we will refer to it as SMAR) between the two state variables introduced with the four parameters $s_{\mathrm{w} 2}, s_{\mathrm{c} 1}, a$, and $b$. All these parameters may be estimated from the soil texture, the soil depth, and the soil water losses. The parameter $a$ is a function of potential evapotranspiration and soil permeability that can be estimated using regression functions such as those proposed by Pan et al. (2003). It should be noted that SMAR may produce values higher than 1 and that these are automatically set equal to 1 .

In order to provide a range of variability of the soil parameters of the model, Table 1 collects the values derived from the experimental investigations by Rawls and Brakensiek (1989) and also reported in Rawls et al. (1993). In particular, the soil porosity $(n)$, the bubbling pressure head $(\psi)$, and the soil permeability at saturation $\left(K_{\mathrm{S}}\right)$ were taken from Rawls et al. (1993), while the values of $s_{\mathrm{W}}$ and $s_{\mathrm{c}}$ have been calculated adopting the Brooks and Corey (1964) model $\left(\psi(s)=\psi_{\mathrm{s}} s^{-1 / m}\right.$, where $m$ is the pore-size index) assuming a soil water potential of $\psi=-1.5 \mathrm{Mpa}$ and $-0.03 \mathrm{Mpa}$, respectively.

Figure 1 shows some examples of the application of SMAR in a short time series of surface soil moisture measured in the first $10 \mathrm{~cm}$ of soil in a dry environment (measurements are taken from the station of Sevilleta, New Mexico, US). This preliminary application is used to show the influence that different model parameters have on the derived root-zone soil moisture, named $s_{2 S M A R}^{*}$. With this specific aim, we plotted the derived soil moisture in the root zone assuming a different combination of parameters changing the values of the soil water loss coefficient (Fig. 1a); the depth of the second soil layer (Fig. 1b); and the soil parameters associated with different soil textures (Fig. 1c). The function $s_{2 S M A R}^{*}$ is obtained via changing the parameters $V_{2}$ and $\mathrm{Zr}_{2}$ in Fig. 1a and b, respectively, while the functions plotted in Fig. 1c are obtained assuming different soil textures using the values reported in Table 1 . In each plot, the remaining parameters have been assumed constant using as reference values the following set of parameters: $n_{1}=n_{2}=0.437$, $s_{w 2}=0.06, s_{\mathrm{c} 2}=0.14, V=2 \mathrm{~cm} \mathrm{day}^{-1}, \mathrm{Zr}_{1}=10 \mathrm{~cm}$, and $\mathrm{Zr}_{2}=100 \mathrm{~cm}$. All $s_{2 \mathrm{SMAR}}^{*}$ time series have been computed assigning the relative saturation at field capacity as the initial value. All functions have been plotted assuming as initial value for the soil moisture in the second soil layer equal to the field capacity.

This preliminary analysis was useful to understand the role of each parameter for the soil moisture dynamics. In particular, the water loss coefficient produces a shift on the function $s_{2 \text { SMAR }}^{*}$, preserving the general pattern with a reduction of the mean value of the soil moisture with the increase of $V_{2}$.
Table 1. Soil parameters associated with different soil textures according to the experiments by Rawls and Brakensiek (1989). ${ }^{\mathrm{a}} \mathrm{Pa}-$ rameters taken from Rawls and Brakensiek (1989) and also reported in Rawls et al. (1993). ${ }^{b}$ The relative saturation at the wilting point and the field capacity have been estimated using the Brooks-Corey

\begin{tabular}{|c|c|c|c|c|c|c|}
\hline Soil type & $\begin{array}{l}n \\
{[-]^{\mathrm{a}}}\end{array}$ & $\begin{array}{l}m \\
{[-]^{\mathrm{a}}}\end{array}$ & $\begin{array}{r}\psi_{\mathrm{s}} \\
{[\mathrm{cm}]^{\mathrm{a}}}\end{array}$ & $\begin{array}{r}K_{\mathrm{s}} \\
{\left[\mathrm{cmd}^{-1}\right]^{\mathrm{a}}}\end{array}$ & $\begin{array}{l}s_{\mathrm{W}} \\
{[-]^{\mathrm{b}}}\end{array}$ & $\begin{array}{l}s_{\mathrm{c}} \\
{[-]^{\mathrm{b}}}\end{array}$ \\
\hline Sand & 0.437 & 0.592 & 7.26 & 504.00 & 0.06 & 0.14 \\
\hline Loamy sand & 0.437 & 0.474 & 8.69 & 146.60 & 0.11 & 0.24 \\
\hline Sandy loam & 0.453 & 0.322 & 14.66 & 62.20 & 0.19 & 0.42 \\
\hline Silty loam & 0.501 & 0.211 & 20.76 & 31.70 & 0.27 & 0.57 \\
\hline Loam & 0.463 & 0.220 & 11.15 & 16.30 & 0.25 & 0.50 \\
\hline Sandy clay loam & 0.398 & 0.250 & 28.08 & 10.30 & 0.34 & 0.62 \\
\hline Silty clay loam & 0.471 & 0.151 & 32.56 & 3.60 & 0.45 & 0.73 \\
\hline Clay loam & 0.464 & 0.194 & 25.89 & 5.50 & 0.40 & 0.67 \\
\hline Sandy clay & 0.430 & 0.168 & 29.17 & 2.90 & 0.51 & 0.75 \\
\hline Silty clay & 0.479 & 0.127 & 34.19 & 2.20 & 0.52 & 0.78 \\
\hline Clay & 0.475 & 0.131 & 37.30 & 1.40 & 0.56 & 0.80 \\
\hline
\end{tabular}
model assuming $\psi=-1.5$ and $-0.03 \mathrm{Mpa}$, respectively.

The impact of the depth of the second layer of soil produces a significant modification on the variability of the soil moisture that increases with the reduction of the $\mathrm{Zr}_{2}$ values. Finally, the soil texture also has a critical role, affecting several model parameters. In the present scheme, it was assumed that the soil texture controls the values of soil porosity, the relative saturation at the field capacity and at the wilting point. These last two parameters impact on the minimum value reached by the $s_{2 \mathrm{SMAR}}^{*}$ and the variability of the soil moisture. In particular, the fluctuations of soil moisture increase for lower values of $s_{\mathrm{c} 1}$. In fact, we observed a continuous reduction in the fluctuations moving from sand to sandy clay soil. In this last case, the value of $s_{\mathrm{c} 1}$ is so high that it inhibits most of the infiltration in the lower soil layer, and as a consequence soil moisture remains almost constant around the value of wilting point. It is necessary to point out that different soil textures have also different permeability, which may affect the value of the soil water loss coefficient, which in the present case was kept constant.

At this point, the comparison between the proposed procedure and the SWI method becomes extremely interesting, and will be described better and in greater detail in the following section.

\subsection{Exponential filter}

In this study, SMAR was compared with the semi-empirical approach (also known as the exponential filter) proposed by Wagner et al. (1999) that has received much attention in the recent years (e.g. Matgen et al., 2012b; Nied et al., 2013; Albergel et al., 2013). This approach was derived from the soil water balance equation assuming that the changes in the soil water content are controlled by a pseudodiffusivity term that allows both positive and negative fluxes from and to the deep layer. These fluxes are all proportional to the relative 

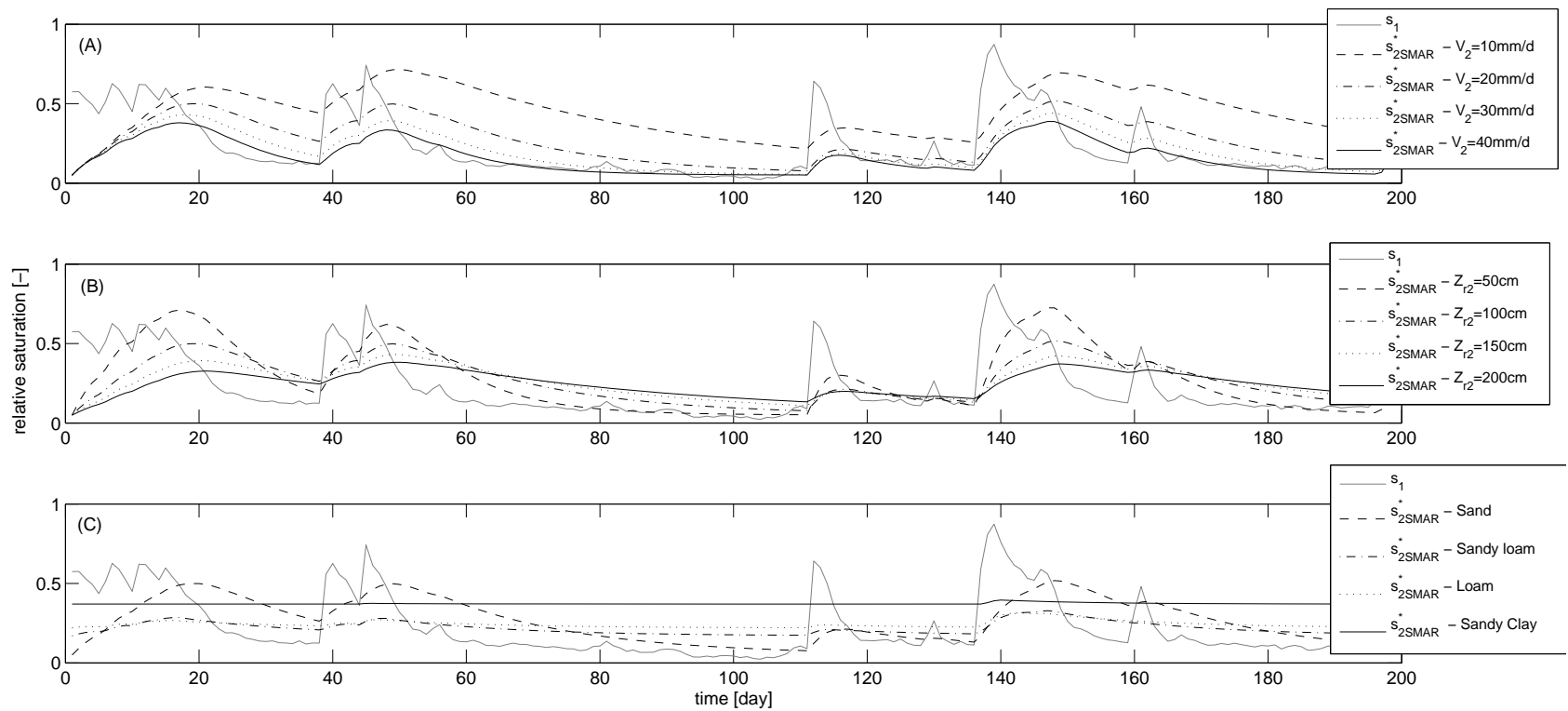

Fig. 1. Examples of application of the SMAR to a time series of surface soil moisture $\left(s_{1}\right.$, relative saturation of the first $10 \mathrm{~cm}$ of soil) for different values of soil water losses (A), rooting depth ratios $(\mathbf{B})$, and soil textures $(\mathbf{C})$. The function $s_{2 \mathrm{SMAR}}^{*}$ is obtained through changing only one parameter in (A) and (B) $\left(V\right.$ and $\mathrm{Zr}_{2}$, respectively) and assigning different soil textures in $(\mathbf{C})$ using the soil parameters reported in Table 1. In each plot, the remaining parameters have been assigned using the following set of reference values $n_{1}=n_{2}=0.437, s_{\mathrm{W} 2}=0.06$, $s_{\mathrm{c} 2}=0.14, V=2 \mathrm{cmday}^{-1}, \mathrm{Zr}_{1}=10 \mathrm{~cm}$, and $\mathrm{Zr}_{2}=90 \mathrm{~cm}$ (measurements are taken from the station of Sevilleta -1 lat. $34^{\circ} 21^{\prime} \mathrm{N}$, long. $106^{\circ} 41^{\prime} \mathrm{W}$; New Mexico, US).

change existing between the surface soil moisture and the deeper soil layer.

Following the same notation as has been used above, the soil water balance equation may be written as

$n \mathrm{Zr} \frac{\mathrm{d} s_{2}}{\mathrm{~d} t}=C\left(s_{1}-s_{2}\right)$

where $t$ is the time and $C$ is a pseudodiffusivity coefficient that depends on the soil properties. This method assumes that the variation of the root-zone soil moisture is linearly related to the difference between the surface and root-zone soil moisture. One may immediately realize that the equation contains only one parameter that is represented by $T=n \mathrm{Zr} / C$, named the characteristic time length.

This approach leads to the development of an exponential filter that has been extensively used in remote sensing applications, but with the limitation of a physical interpretation of the parameter $T$. The root-zone soil moisture can be obtained through the knowledge of the surface soil moisture and a parameter $T$. The recursive formulation of the method relies on (Albergel et al., 2008)

$s_{2}^{*}\left(t_{j}\right)=s_{2}^{*}\left(t_{j-1}\right)+K_{j}\left[s_{1}\left(t_{j}\right)-s_{2}^{*}\left(t_{j-1}\right)\right]$,

where $s_{2}^{*}\left(t_{j}\right)$ is the soil moisture of the second layer estimated through the exponential filter (usually defined as the soil water index). The gain $K_{j}$ at time $t_{j}$ is given by (in a re- cursive form)

$$
K_{j}=\frac{K_{j-1}}{K_{j-1}+e^{-\left(\frac{t_{j}-t_{j-1}}{T}\right)}}
$$

and it ranges between 0 and 1 . For the initialization of this filter, $K_{1}$ and $s_{2}^{*}\left(t_{1}\right)$ were set to 1 and $s_{2}\left(t_{1}\right)$, respectively.

\section{Data description: in situ observations}

\subsection{The AMMA database}

The proposed method (SMAR) was tested using field measurements at various depths of three sites of the AMMA database. The AMMA database user interface for accessing local and satellite data is found at AMMA Database (2014). These and other soil moisture products from other projects have been collected in the International Soil Moisture Network (ISMN) database ${ }^{1}$ (e.g. Dorigo et al., 2011). The data set presented in this paragraph was downloaded from the ISMN database.

The AMMA programme is an international long-term collaboration to study the climatic and environmental feedback mechanisms involved in the African monsoon, and in some of its consequences on society and human health. The programme, which started in 2004, has developed a network

\footnotetext{
${ }^{1}$ Now routinely available at ISMN (2014).
} 
of ground-based observation stations over sub-Saharan West Africa, and several intensive measurement campaigns (see Redelsperger et al., 2006). In particular, three mesoscale sites were implemented in Benin (Pellarin et al., 2009b), Mali (de Rosnay et al., 2009), and Niger (Pellarin et al., 2009a), providing a large amount of information on soil moisture and many other variables. In the present paper, we focused on the point measurements taken at the sites of Nalohou-Mid and Nalohou-Top in Benin, Agoufou in Mali, and Wankama and Tondikiboro in Niger. The climate conditions of these three sites are significantly different in terms of precipitation, ranging between 300, 550, and 1200 mm year $^{-1}$ for Mali, Niger, and Benin, respectively (AMMA-CATCH, 2014).

Soil moisture data are collected over the root-zone profile at different depths starting from the surface (at $5 \mathrm{~cm}$ depth) down to $135 \mathrm{~cm}$ depth. For the scope of the present application, the relative saturation values at $5 \mathrm{~cm}$ depth has been adopted as a reference surface measurement, while the relative saturation over the root profile has been computed averaging the soil moisture measurements below the surface layer.

For the sake of simplicity, we will first focus on the Tondikiboro station, which provides six soil moisture measurements over the soil profile starting from $5 \mathrm{~cm}$ depth down to $135 \mathrm{~cm}$. The installation is composed of six water content reflectometers (CS616 - Campbell Scientific Inc., Logan, Utah, USA) placed along the soil column with the geometry schematically described in Fig. 2. Measurements are taken with two horizontal probes at the depth of $5 \mathrm{~cm}$ and with four vertical probes that provide a measure over a soil layer comparable to the probe length (about $30 \mathrm{~cm}$ ).

The time series of soil moisture measurements is given in Fig. 3, where the values of relative saturation for each probe are plotted in two panels that provide an overview of the soil moisture dynamics at the two sites located in Niger. These panels provide a complete picture of the temporal dynamics of soil moisture over a period of more than 3 years (13 May 2006-31 December 2009).

Hourly time series have been aggregated at daily scale with the aim to evaluate the acceptability of our simplifying assumption for the present case study. A preliminary analysis on the available data was carried out to study the water losses using the time series of relative saturation in the first layer of soil (averaged value obtained from two horizontal probes at $5 \mathrm{~cm}$ depth) and the averaged value of the relative saturation of soil in the lower portion of soil $(10-135 \mathrm{~cm})$. These two values are named $s_{1}$ and $s_{2}$, respectively. The time series contains some useful information to investigate the actual values of soil water losses. In particular, considering the period soon after a rainfall event the loss rate can be estimated by the relative changes in the soil moisture or relative saturation from one day to the other. Plotting the relative changes of soil moisture as a function of the relative saturation of soil at different depths and for the entire volume of soil investigated provides a preliminary description of the shape assumed by

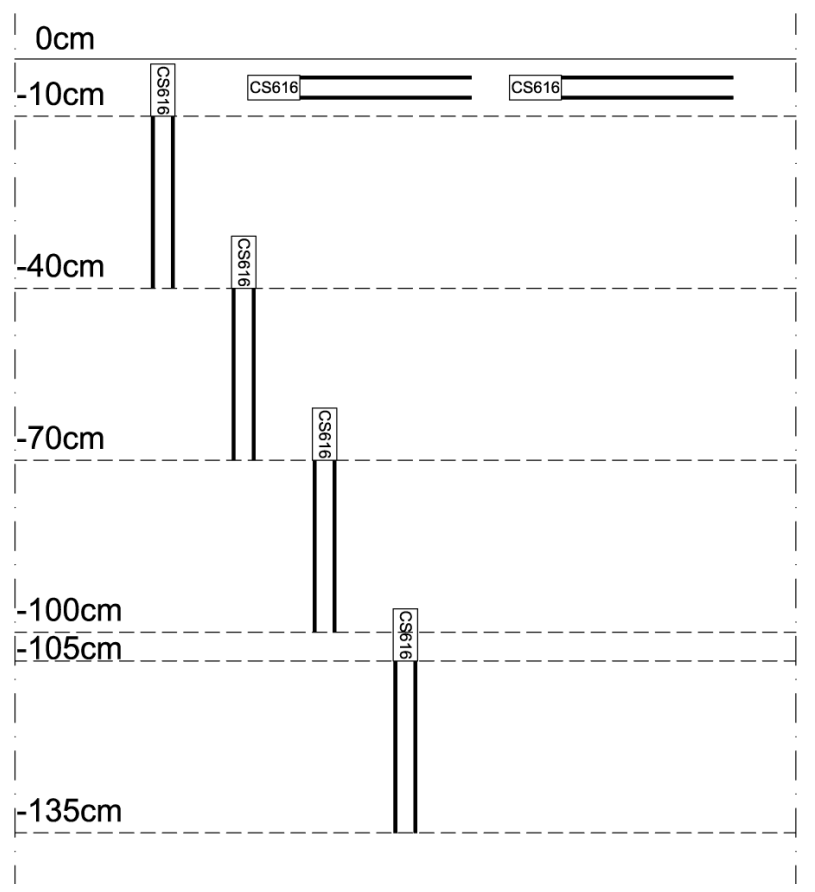

Fig. 2. Relative position of the six soil moisture probes installed at the station of Tondikiboro in Niger.

the loss function in the present study case. These changes are plotted in Fig. 4 as a function of the relative saturation at time $t_{j-1}$ for both the soil moisture at $5 \mathrm{~cm}$ depth (Fig. 4a) and for the relative saturation of the lower layer of soil obtained from the average of all the probes' measurements below the first layer (Fig. 4b). These graphs have been obtained from the series of the relative changes of relative saturation of the soil at time $t_{j}$ and $t_{j-1}$ excluding all negative values and all positive variations due a rainfall event. Both graphs show a significant scattering that may be due to the seasonality of the process or to rainfall not being detected, but the linear approximation seems a reasonable one.

The graphs provide a significant source of information for the description of soil moisture dynamics describing a first approximation of the soil water loss function with some scatter. Moreover, the two graphs highlight the different rate of changes observed at the superficial soil layer with respect to the rate of change observed over the entire soil profile with a significant faster drying process in the surface layer. This result may be due to a higher root density in the surface layer with respect to the lower layers and also by the fact that the surface layer is more influenced by the evaporation process. The cloud of points shows that the soil water losses are negligible when the relative saturation of the soil is below a certain value $(\sim 0.08)$. This value may be set as wilting point for the SMAR method when this information is available. 

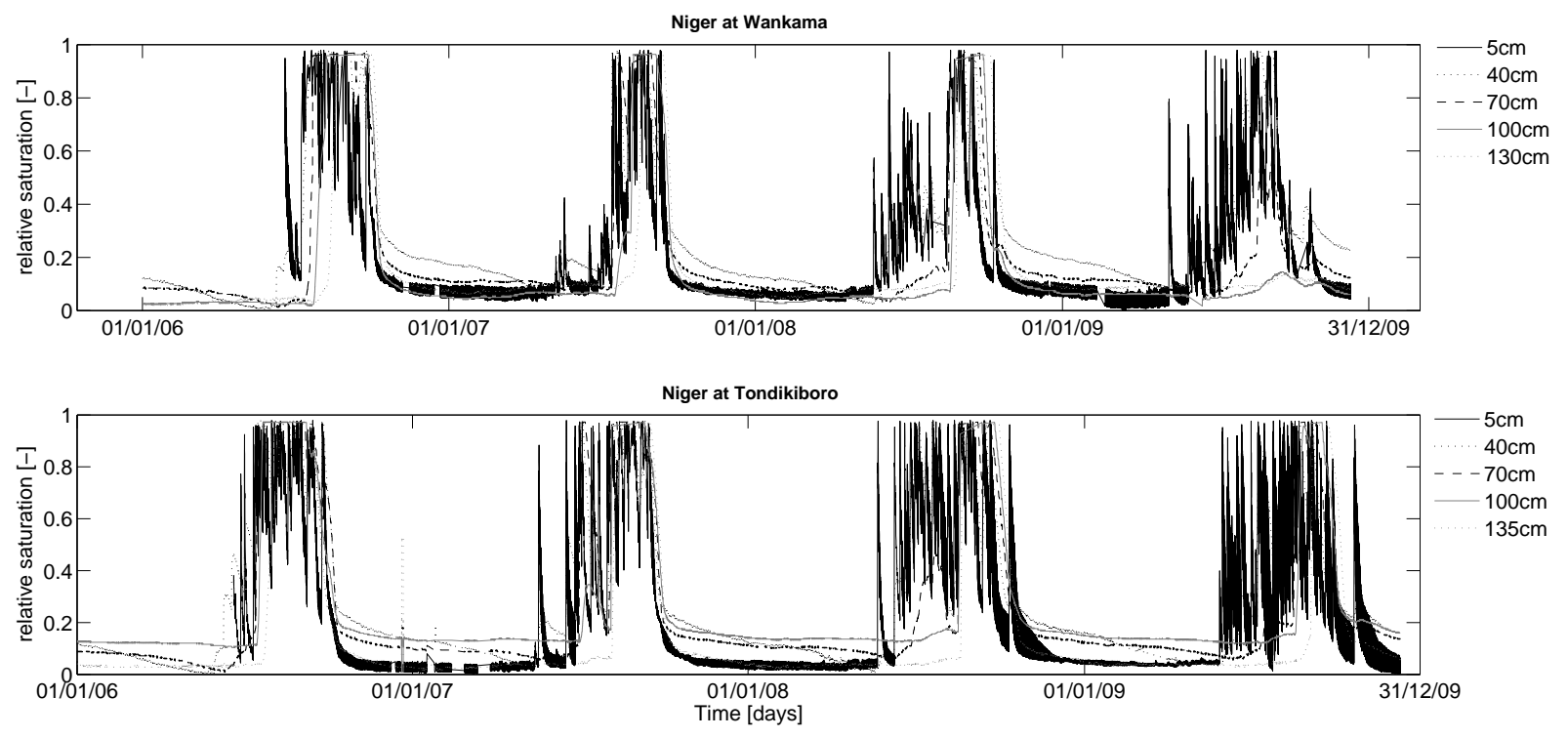

Fig. 3. Time series of the point measurements of the relative saturation of soil at the two stations of the AMMA network Wankama and Tondikiboro in Niger. Point measurements provide a good description of the soil moisture variations along the soil profile with five or six measurements at different depths ranging from $5 \mathrm{~cm}$ down to $100-135 \mathrm{~cm}$. Data refer to the period 13 May 2006-31 December 2009.

\subsection{The SCAN database}

The Soil Climate Analysis Network (SCAN) is composed of more than 190 stations located in 40 states of the US covering different climatic and physical conditions (e.g. Schaefer et al., 2007). It represents an excellent database for the description of the soil moisture and profile under several additional climatic conditions. Measurements are collected with measuring the dielectric devices at approximately 5, 10, 20, 50 , and $100 \mathrm{~cm}$ depth. For the scope of the paper, we selected three of stations in the state of New Mexico, which is characterized by a semiarid climate. The choice was influenced by the opportunity to use the pedological description of the soil column available for these three sites. Such information turned out to be extremely useful for the application of the presented methodology.

The stations selected are Adams Ranch \#1, Crossroads, and Willow Wells in New Mexico (US), where continuous soil moisture measurements are available for a period of about $4-5$ years. The climatic conditions are quite different from those of the sites in Africa, where we observed a strong seasonal fluctuation in rainfall that is reflected in the dynamics of soil moisture. In the present case, this seasonality is limited and in general the soil moisture conditions are drier.

The pedological report available on the web site of SCAN allowed for definition of the soil texture characteristics of the first (the first $10 \mathrm{~cm}$ ) and the second layer of soil (assumed equal to the remaining $90 \mathrm{~cm}$ ). We generally found that the upper layer has a higher sand content compared to the lower soil layer. In fact, the second layer of soil was composed of sandy loam in all cases, while the first layer was made of
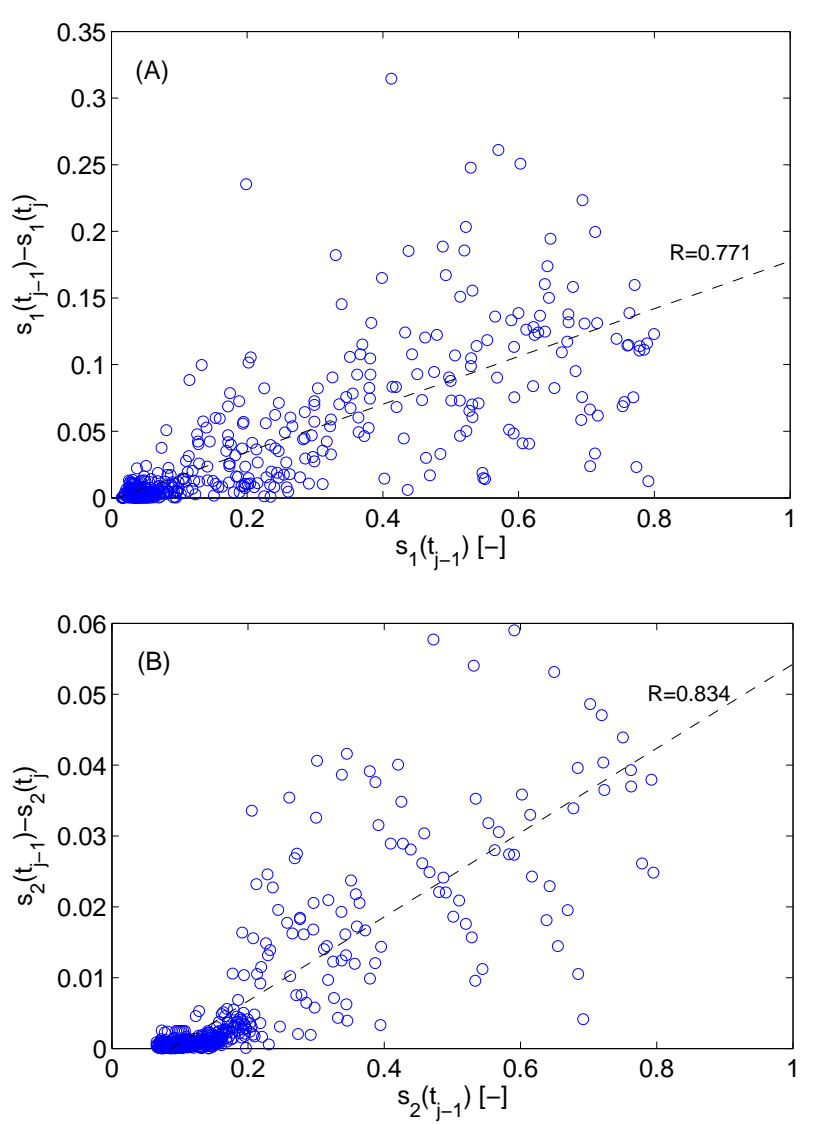

Fig. 4. Changes in relative soil saturation as a function of the relative saturation of the soil in the first (A) and second layer (B). The graph has been derived from the time series of soil moisture at the station of Tondikiboro in Niger. 

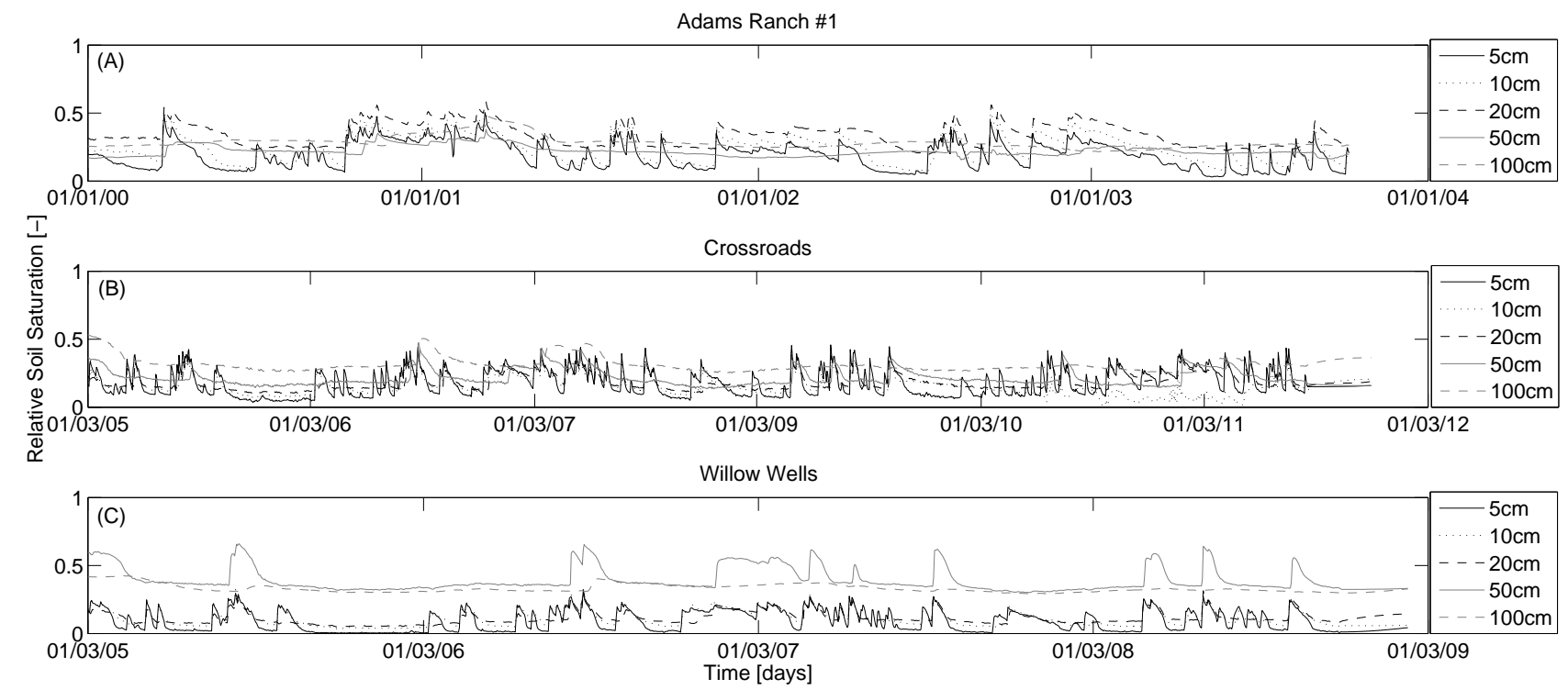

Fig. 5. Time series of the point measurements of the soil relative saturation at the three stations of the SCAN network considered in the present study: Adams Ranch \#1 (A), Crossroads (B), and Willow Wells (C) in New Mexico, US. Probes provide soil moisture measurements at depths ranging from $5 \mathrm{~cm}$ down to $100 \mathrm{~cm}$.

sand at Willow Wells and loamy sand at Adams Ranch \#1 and Crossroads.

A preliminary description of the soil moisture measurements is given in Fig. 5, where the relative saturation of soil at different depths is plotted for these three stations. This plot provides a complete overview on the variability of the soil moisture along the soil column.

\section{Model application}

\subsection{Application on the AMMA database}

The SMAR approach was applied to soil measurements available in West Africa, and in particular for the Wankama and Tondikiboro stations in Niger. These soil moisture measurements along with the other point measurements (Nalohou-Mid, Nalohou-Top, and Agoufou) form an excellent database that well describes the soil moisture along the root-zone profile. According to this, we have used the surface soil moisture measurements at $5 \mathrm{~cm}$ depth to predict the soil moisture in the lower layer of the soil, where the relative saturation is measured at various depths.

SMAR contains in total seven parameters $\left(s_{\mathrm{w} 2}, s_{\mathrm{c} 1}, \mathrm{Zr}_{1}\right.$, $\mathrm{Zr}_{2}, n_{1}, n_{2}, V_{2}$ ) that can be related to physical characteristics of the soil profile. All of these parameters can be assigned to four further parameters $\left(a, b, s_{\mathrm{c} 1}, s_{\mathrm{w} 2}\right)$, as explained in the previous section. In a preliminary application without calibration, we assigned to each of those a value consistent with the physical characteristics of the site under investigation:

- Parameters $s_{\mathrm{W} 2}, s_{\mathrm{c} 1}, n_{1}$, and $n_{2}$ can be assigned according to the soil texture of the site. In particular, both sites are characterized by sandy soils, and for this reason a first approximation for these parameters can be obtained from values taken from the literature (see characteristics of sand soil in Table 1). In both cases, we assigned the following values: $s_{\mathrm{w} 2}=0.06$, $s_{\mathrm{c} 1}=0.14, n_{1}=0.437$, and $n_{2}=0.437$. Eventually, the value of $s_{\mathrm{w} 2}$ may also be extrapolated by the graph of Fig. 4a, but in the present case only parameters taken from the literature were adopted.

- Parameter $a=V_{2} /\left(n_{2} Z_{2}\left(1-s_{\mathrm{W}}\right)\right)$ is computed based on the characteristics of the soil and of the climate. In particular, soil parameters were defined based on the soil texture of the site under investigation, the depth of the second layer of soil, $\mathrm{Zr}_{2}$, was defined according to the depth of the deepest probe installed, and, finally, the value of the soil water loss coefficient was defined taking into account both the high permeability of the soil and also the high evapotranspiration losses observed at these specific sites. Consequently, we assigned the following values for $n=0.437-\mathrm{Zr}_{2}=$ $120 \mathrm{~cm}$ at Wankama and $125 \mathrm{~cm}$ at Tondikiboro - and $V$ was set equal to $20 \mathrm{~mm} \mathrm{day}^{-1}$.

- Finally, the parameter $b$ was estimated using Eq. (3) assuming a depth of $10 \mathrm{~cm}$ for the first layer of soil (considering that the probes at $5 \mathrm{~cm}$ depth are horizontal and provide a description of a volume around the probe that may be assumed representative of a soil depth of 10; see Fig. 2) and the second one considered with a depth equal to the depth of the last probe minus $10 \mathrm{~cm}$ for the second one. 

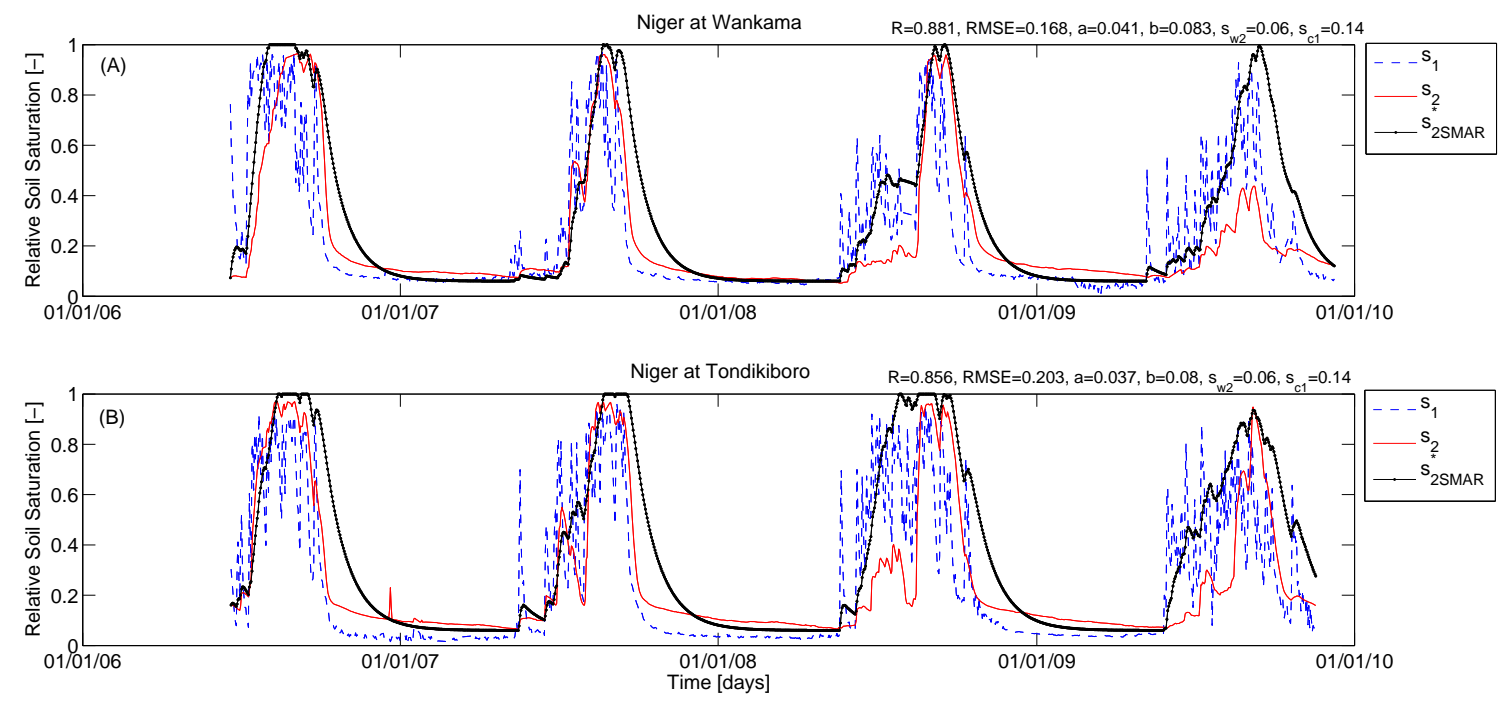

Fig. 6. Comparison between the relative saturation at $5 \mathrm{~cm}\left(s_{1}\right)$ and the averaged value over 100,130 , and $135 \mathrm{~cm}$ depth, and the filtered value ( $s_{2 \text { SMAR }}^{*}$ - black line) obtained with SMAR for two sites located at Wankama (A) and Tondikiboro (B), respectively. Results have been obtained assigning parameters based on the physical characteristics of the study cases.

The results of this preliminary application are given in Fig. 6, where one can see the good performance of the method in capturing the trend in the signal of soil moisture in the lower soil layer over a temporal window of 4 years. The graph provides a description of the application of SMAR to the two time series measured in Niger with the parameters assigned as described above. The model reproduces the seasonality of the soil moisture signal very well, with some discrepancies during the transition phases. Correlations of $R=0.88$ and $R=0.85$ and a root-mean-square errors (RMSE) of 0.168 and 0.203 are found for Wankama and Tondikiboro stations, respectively.

The same model was also used over several time series available on the AMMA network using the three super sites (Benin, Niger, and Mali) using the averaged values of relative saturation estimated from several point measurements, using all points that provide a complete description of the root profile, and the averaged values estimated over the three super sites (Benin, Niger, and Mali). In fact, $t$ The AMMA network was built with the specific aim to monitor the averaged soil moisture over three super sites of $25 \times 25 \mathrm{~km}^{2}$. These data are particularly useful for shedding light on the impact of different scales on the use of SMAR.

In this case, the model was calibrated for all parameters using the RMSE between the averaged relative saturation of the lower layer of soil and the filtered time series of $s_{1}$ as an objective function. This calibration procedure was performed for both the SWI method (optimizing the parameter $T$ ) and SMAR (optimizing the parameters $a, b, s_{\mathrm{w} 2}$, and $s_{\mathrm{c} 1}$ ), obtaining the results summarized in Table 2. In general, the SMAR procedure produced better results in terms of correlation and RMSE, but this is not surprising considering the number of parameters in the second equation. Nevertheless, it is encouraging from our perspective that the calibration parameters are very close to those estimated based on the physical information available (soil texture, potential evapotranspiration, and soil permeability) for the site confirming the physical consistency of the methodology.

More specifically, the result of the application of the two procedures for the super sites is given in Fig. 7, where one can see the behaviour of the two expressions when applied to this data set. Apart from the general evaluation of the performances that are influenced by the different level of complexity of the two schemes, it is interesting to note that the calibrated parameters of SMAR applied to the three super sites are closely related to the values obtained for the point measurements. In particular, it can be observed in Table 1 that the parameters $a$ and $s_{\mathrm{w} 2}$ seem to be less sensitive to the change in scale, while the parameters $b$ and $s_{\mathrm{c} 1}$ display a higher variability at the two analysed scales. In general, the calibrated values of the parameters reflect the physical characteristics of the sites in terms of soil water losses and other characteristics.

\subsection{Application on the SCAN database}

The SMAR approach was applied to soil measurements available in New Mexico. Using the same procedure described above for the AMMA data, we assigned the set of model parameters based on the available information from the site. In this case, we had the advantage of a better description of the soil texture that allowed for differentiating between those parameters referring to the first layer and those referring to the second one. Following the same scheme 

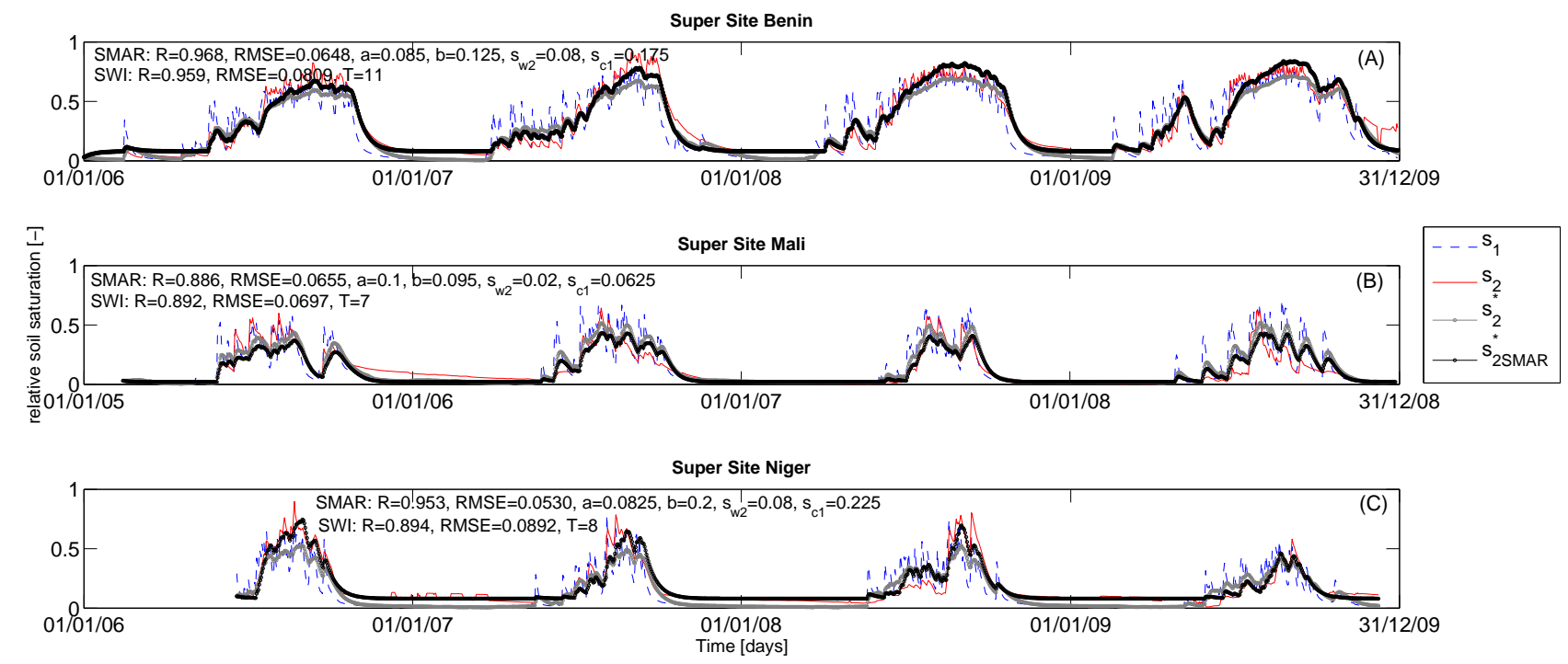

Fig. 7. Comparison between the relative saturation measured at $5 \mathrm{~cm}\left(s_{1}\right)$ and the averaged value in the second soil layer of depth $\left(s_{2}\right)$, the filtered value $\left(s_{2 S M A R}^{*}\right)$ obtained with SMAR and the filtered value obtained with the exponential filter $\left(s_{2}^{*}\right)$ for three super sites located respectively in Benin (A), Mali (B), and Niger (C). Results describe the application of SMAR and the exponential filter (SWI) method where all parameters have been calibrated optimizing the RMSE.

Table 2. Summary of the results of the calibration with the SMAR and SWI methods on the time series of the AMMA database analysed herein.

\begin{tabular}{|c|c|c|c|c|c|c|c|c|c|}
\hline & $\begin{array}{l}a \\
\text { [days }^{-1} \text { ] }\end{array}$ & $\begin{array}{l}b \\
{[-]}\end{array}$ & $\begin{array}{l}s_{\mathrm{W} 2} \\
{[-]}\end{array}$ & $\begin{array}{l}s_{\mathrm{c} 1} \\
{[-]}\end{array}$ & R (SMAR) & RMSE (SMAR) & $\begin{array}{c}T \\
\text { [days] }\end{array}$ & R (SWI) & RMSE (SWI) \\
\hline \multicolumn{10}{|c|}{ Local measurements - Benin } \\
\hline Nalohou-Mid & 0.06 & 0.20 & 0.06 & 0.01 & 0.966 & 0.0145 & 4 & 0.963 & 0.0545 \\
\hline Nalohou-Top & 0.05 & 0.25 & 0.08 & 0.04 & 0.943 & 0.0183 & 12 & 0.906 & 0.07203 \\
\hline Mean values & 0.06 & 0.23 & 0.07 & 0.03 & & & 8 & & \\
\hline \multicolumn{10}{|c|}{ Local measurements - Mali } \\
\hline Agoufou & 0.10 & 0.15 & 0.02 & 0.08 & 0.898 & 0.0155 & 28 & 0.773 & 0.0456 \\
\hline \multicolumn{10}{|c|}{ Local measurements - Niger } \\
\hline Wankama & 0.06 & 0.11 & 0.10 & 0.28 & 0.932 & 0.089 & 14 & 0.911 & 0.102 \\
\hline Tondikiboro & 0.09 & 0.20 & 0.10 & 0.39 & 0.925 & 0.104 & 10 & 0.897 & 0.124 \\
\hline Mean values & 0.07 & 0.15 & 0.10 & 0.33 & & & 12 & & \\
\hline \multicolumn{10}{|c|}{ Averaged values at $25 \mathrm{~km} \times 25 \mathrm{~km}$ scale } \\
\hline Super site Benin & 0.09 & 0.13 & 0.08 & 0.18 & 0.968 & 0.0647 & 11 & 0.959 & 0.08 \\
\hline Super site Mali & 0.10 & 0.10 & 0.02 & 0.07 & 0.885 & 0.0655 & 7 & 0.892 & 0.069 \\
\hline Super site Niger & 0.08 & 0.20 & 0.08 & 0.23 & 0.951 & 0.0541 & 8 & 0.894 & 0.0891 \\
\hline
\end{tabular}

adopted in the previous section, we assigned the following parameters to three considered case studies:

- Soil parameters were assigned based on the soil characteristics of the sites. We assigned the following soil parameters:

$n_{1}=0.437, n_{2}=0.453, s_{\mathrm{c} 1}=0.24, s_{\mathrm{w} 2}=0.19$, for Adams Ranch \#1;

$n_{1}=0.437 ; n_{2}=0.453 ; s_{\mathrm{c} 1}=0.24, s_{\mathrm{w} 2}=0.19$ for Crossroads; $n_{1}=0.437 ; n_{2}=0.453 ; s_{\mathrm{c} 1}=0.14, s_{\mathrm{w} 2}=0.19$ for Willow Wells.

- Considering that the potential evapotranspiration and soil permeability of these sites may produce values of soil water losses similar to those of the AMMA sites, we assigned the same value of $V_{2}=20 \mathrm{~mm} \mathrm{day}^{-1}$. Parameter $a$ was computed using Eq. (2) and adopting the soil parameters derived from the soil texture.

- The parameter $b$ was estimated using Eq. (3) and assuming the first layer of soil of $Z_{1}=10 \mathrm{~cm}$ and the second one of $\mathrm{Zr}_{2}=90 \mathrm{~cm}$. 


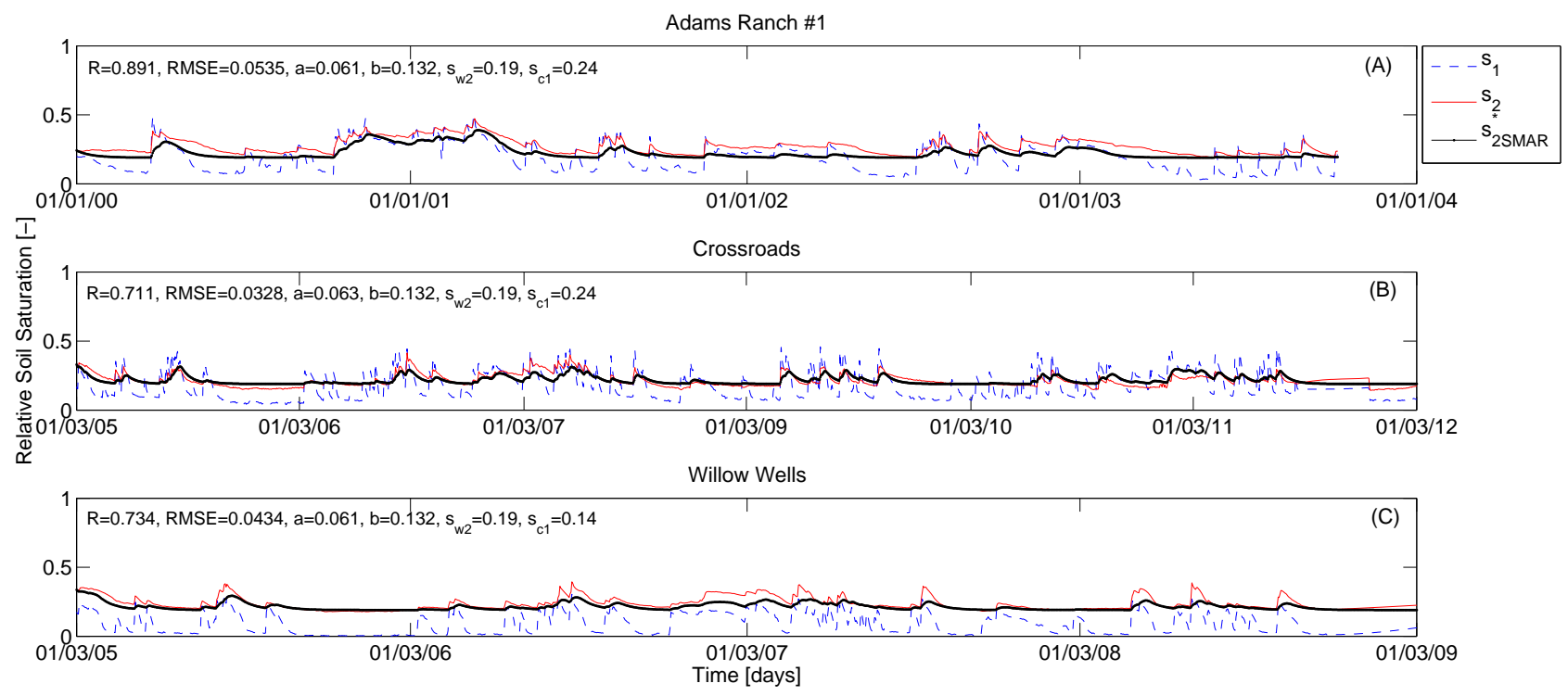

Fig. 8. Comparison between the relative saturation of the surface soil layer $\left(s_{1}\right)$ and the averaged value over $90 \mathrm{~cm}$ depth $\left(s_{2}\right)$, and the filtered value ( $s_{2 \text { SMAR }}^{*}$ - black line) obtained with SMAR for three sites located at Adams Ranch \#1 (A), Crossroads (B), and Willow Wells (C), respectively. Results have been obtained assigning parameters based on the physical characteristics of the study area.

The results of this preliminary application are given in Fig. 8, where one can see the good performance of the method in capturing the trend of the signal of soil moisture in the lower soil layer. The graph provides a description of the application of SMAR to the time series measured in New Mexico with the parameters assigned. The application of SMAR without calibration provided encouraging results that are corroborated by the observed correlation coefficients and the RMSE between the observation and the reconstructed values of the relative saturation of the second layer of soil. In particular, we observed a correlation of $R=0.89,0.71$, and 0.73 and a RMSE of $0.053,0.0328$, and 0.0434 for Adams Ranch \#1, Crossroads, and Willow Wells stations, respectively.

SMAR was also compared with SWI in order to provide a complementary comparison of the performances of the two methods on a different context. Such comparison was carried out with a calibration of both models aimed at the minimization of the RMSE. The result of the application of the two procedures is shown in Fig. 9 for the three SCAN sites described. Here the performances of the SMAR algorithm provide an excellent result compared with SWI. Here one may appreciate the performances of the two procedures after calibration.

In addition to the three mentioned stations, we also considered four additional stations in New Mexico where the soil pedon report was not available. For this reason, these data were only used for a comparison with SWI. The results of this application can be found in Table 3 for the soil moisture station of the SCAN network in New Mexico. It can be observed that, apart from the general evaluation of the performances that are influenced by the different level of complexity of the two schemes, it is interesting to note that SMAR produces better results both in terms of $R$ values and RMSE. Nevertheless, SMAR fails in the interpretation of the soil moisture at the station of Los Lunas, where SWI also performed very poorly. This may be due to errors in the data or in a limitation of the two procedures. In general, the calibrated values of the parameters reflect the physical characteristics of the sites in terms of soil water losses and other characteristics.

The analysis presented provides a preliminary comparison between the two methods, highlighting the good performance of SMAR in dry environments. Nevertheless, a more accurate/comprehensive intercomparison between the two models could be performed using the AIC and BIC methods (e.g. Ye et al., 2008) to assess model fit, but would be penalized by the number of estimated parameters.

\section{Conclusions}

In this paper, we introduced a new methodology, named SMAR, for the description of soil moisture in the root zone based on the time series of surface soil moisture data. SMAR has a physically consistent structure, with parameters that may be estimated from the physical characteristics of the site under investigation. Results obtained using as much of the available physical information as possible provided good results.

The methodology was also applied using measured soil moisture, providing prediction of the relative saturation over two significantly different spatial scales. Regarding the point 


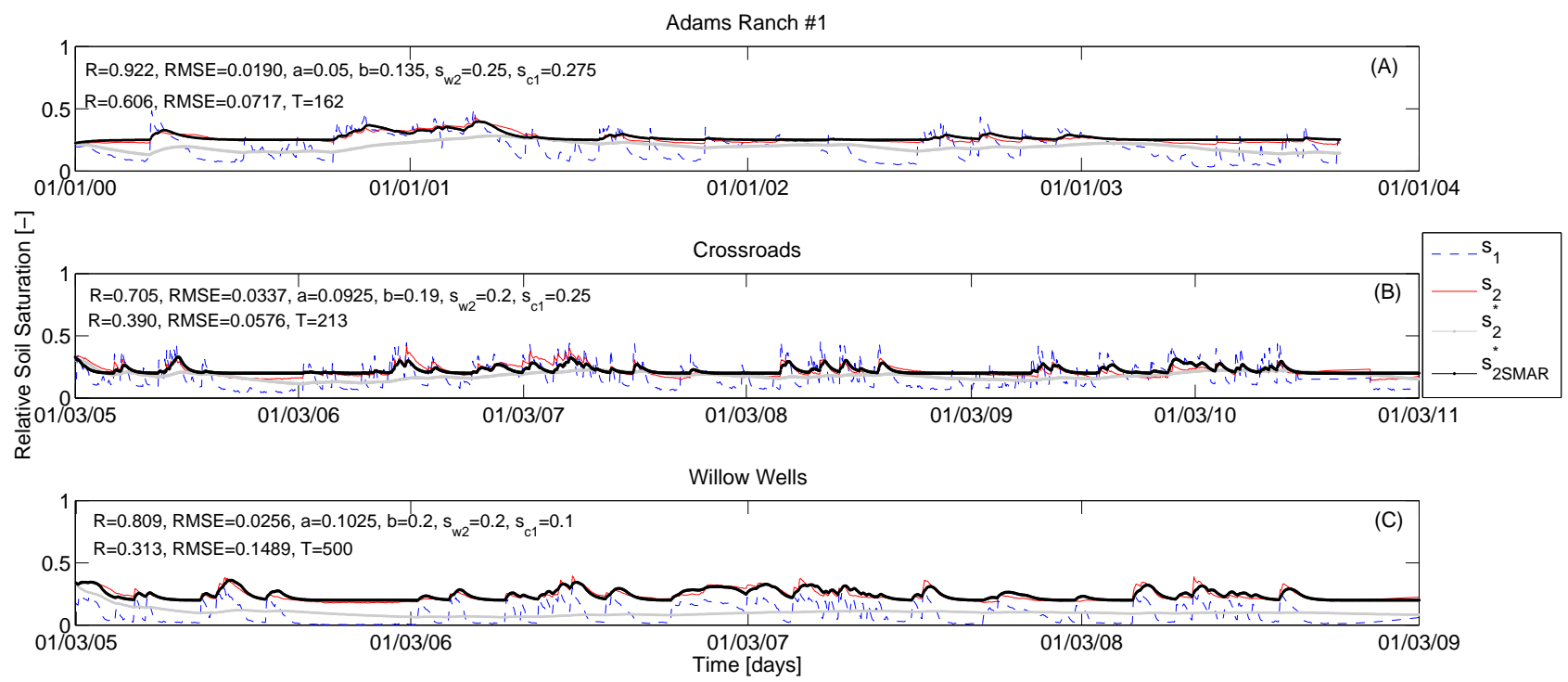

Fig. 9. Comparison between the relative saturation of the surface soil layer $\left(s_{1}\right)$ and the averaged value over the first $90 \mathrm{~cm}$ of depth $\left(s_{2}\right)$, the filtered value $\left(s_{2 \mathrm{SMAR}}^{*}\right)$ obtained with SMAR and the filtered value obtained with the exponential filter $\left(s_{2}^{*}\right)$ for three sites located at Adams Ranch \#1 (A), Crossroads (B), and Willow Wells $(\mathbf{C})$, respectively. Results describe the application of SMAR and the exponential filter (SWI) method, where all parameters have been calibrated optimizing the RMSE.

Table 3. Summary of the results of the calibration with the SMAR and SWI methods on the time series of the SCAN database.

\begin{tabular}{|c|c|c|c|c|c|c|c|c|c|}
\hline Station & $\begin{array}{l}a \\
{\left[\text { days }^{-1}\right]}\end{array}$ & $\begin{array}{l}b \\
{[-]}\end{array}$ & $\begin{array}{l}s_{\mathrm{W} 2} \\
{[-]}\end{array}$ & $\begin{array}{l}s_{\mathrm{c} 1} \\
{[-]}\end{array}$ & R (SMAR) & RMSE (SMAR) & $\begin{array}{c}T \\
\text { [days] }\end{array}$ & R (SWI) & RMSE (SWI) \\
\hline Adams Ranch \#1 & 0.05 & 0.14 & 0.25 & 0.28 & 0.92 & 0.02 & 162 & 0.61 & 0.07 \\
\hline Alcalde & 0.06 & 0.05 & 0.23 & 0.24 & 0.91 & 0.02 & 43 & 0.81 & 0.07 \\
\hline Crossroads & 0.09 & 0.19 & 0.20 & 0.25 & 0.76 & 0.03 & 73 & 0.62 & 0.05 \\
\hline Jordana Exp. Range & 0.05 & 0.05 & 0.05 & 0.01 & 0.88 & 0.02 & 59 & 0.88 & 0.04 \\
\hline Los Lunas & 0.05 & 0.20 & 0.33 & 0.29 & 0.36 & 0.08 & 500 & -0.59 & 0.19 \\
\hline Sevilleta & 0.05 & 0.17 & 0.23 & 0.18 & 0.81 & 0.03 & 500 & 0.68 & 0.14 \\
\hline Willow Wells & 0.08 & 0.20 & 0.20 & 0.13 & 0.90 & 0.02 & 189 & 0.45 & 0.14 \\
\hline
\end{tabular}

measurements, SMAR has been applied using available information in order to infer parameter values. The preliminary application carried out without the need of calibration provided a satisfying result both in terms of $R$ values and RMSE. In order to explore the potential of this new formulation, its performances have been compared with the results obtained through the simple exponential filter proposed by Wagner et al. (1999). Both methods have been used after calibration on several time series of the AMMA and the SCAN. The comparison highlighted that this procedure may provide some improvements in semiarid environments. Moreover, the set of parameters obtained from calibration is consistent with the physical characteristics of the studied area.

The proposed method may be improved by including a soil loss function that accounts for the non-linearity of this process. This step is straightforward, but will incorporate a significant number of additional parameters in the proposed re- lationship, while in the present form the equation provides an interesting, descriptive functional relationship between two variables of extreme interest.

Acknowledgements. The authors wish to acknowledge Wolfgang Wagner and the second, anonymous reviewer for their stimulating comments. Moreover, we are particularly grateful to Thierry Pellarin for his valuable help in providing us all the necessary data for the study. Finally, we take this opportunity to remember the co-author Florisa Melone, who sadly passed away on 28 October 2012. Our sole consolation is that we had the honour and privilege of working with her, but even more the joy of her friendship.

Edited by: S. Seneviratne 


\section{References}

Albergel, C., Rüdiger, C., Pellarin, T., Calvet, J.-C., Fritz, N., Froissard, F., Suquia, D., Petitpa, A., Piguet, B., and Martin, E.: From near-surface to root-zone soil moisture using an exponential filter: an assessment of the method based on in-situ observations and model simulations, Hydrol. Earth Syst. Sci., 12, 1323-1337, doi:10.5194/hess-12-1323-2008, 2008.

Albergel, C., Dorigo, W., Balsamo, G., Muñoz-Sabater, J., de Rosnay, P., Isaksen, L., Brocca, L., de Jeu, R., and Wagner, W.: Monitoring multi-decadal satellite earth observation of soil moisture products through land surface reanalyses, Remote Sens. Environ., 138, 77-89, doi:10.1016/j.rse.2013.07.009, 2013.

AMMA: AMMA-CATCH, 2014: Hydrological and meteorological observatory on West Africa, available at: http://www. amma-catch.org, last access: December 2013, 2014.

AMMA Database: AMMA Data User Interface, available at: http: //database.amma-international.org/, last access: December 2013, 2014.

Brocca, L., Melone, F., Moramarco, T., Wagner, W., Naeimi, V., Bartalis, Z., and Hasenauer, S.: Improving runoff prediction through the assimilation of the ASCAT soil moisture product, Hydrol. Earth Syst. Sci., 14, 1881-1893, doi:10.5194/hess-141881-2010, 2010.

Brocca, L., Moramarco, T., Melone, F., Wagner, W., Hasenauer, S., and Hahn, S.: Assimilation of surface and root-zone ASCAT soil moisture products into rainfall-runoff modelling, IEEE T. Geosci. Remote, 50, 2542-2555, 2012.

Brooks, R. H. and Corey A. T.: Hydraulic properties of porous media, Hydrol. Pap. 3, Colorado State Univ., Fort Collins, USA, 1964.

Ceballos, A., Scipal, K., Wagner, W., and Mart?nez-Fernandez, J.: Validation of ERS Scatterometer-Derived Soil Moisture Data in the Central Part of the Duero Basin, Spain, Hydrol. Process., 19, 1549-1566, 2005.

Crow, W. T., Kustas, W. P., and Prueger, J. H.: Monitoring rootzone soil moisture through the assimilation of a thermal remote sensing-based soil moisture proxy into a water balance model, Remote Sens. Environ., 112, 1268-1281, 2008.

De Lange, R., Beck, R., Van De Giesen, N., Friesen, J., De Wit, A., and Wagner, W.: Scatterometer-derived soil moisture calibrated for soil texture with a onedimensional water-flow model, IEEE Trans. Geosci. Remote Sens., 46, 4041-4049, doi:10.1109/TGRS.2008.2000796, 2008.

de Rosnay, P., Gruhier, C., Timouk, F., Baup, F., Mougin, E., Hiernaux, P., Kergoat, L., and LeDantec, V.: Multi-scale soil moisture measurements at the Gourma meso-scale site in Mali, J. Hydrol., 375, 241-252, 2009.

Dorigo, W. A., Wagner, W., Hohensinn, R., Hahn, S., Paulik, C., Xaver, A., Gruber, A., Drusch, M., Mecklenburg, S., van Oevelen, P., Robock, A., and Jackson, T.: The International Soil Moisture Network: a data hosting facility for global in situ soil moisture measurements, Hydrol. Earth Syst. Sci., 15, 1675-1698, doi:10.5194/hess-15-1675-2011, 2011.

Escorihuela, M., Chanzy, A., Wigneron, J., and Kerr, Y.: Effective soil moisture sampling depth of L-band radiometry: a case study, Remote Sens. Environ., 114, 995-1001, 2010.

Gao, H., Wood, E. F., Jackson, T. J., Drusch, M., and Bindlish, R.: Using TRMM/TMI to Retrieve Surface Soil Moisture over the
Southern United States from 1998 to 2002, J. Hydrometeorol., 7, 23-38, 2006.

Green, W. H. and Ampt, G.: Studies of soil physics, part I - the flow of air and water through soils, J. Agr. Sci., 4, 1-24, 1911.

ISMN (International Soil Moisture Network): The ISMN Data Portal, available at: http://ismn.geo.tuwien.ac.at, last access: December 2013, 2014.

Laio, F.: A vertically extended stochastic model of soil moisture in the root zone, Water Resour. Res., 42, W02406, doi:10.1029/2005WR004502, 2006.

Li, F., Crow, W. T., and Kustas, W. P.: Towards the estimation of root-zone soil moisture via the simultaneous assimilation of thermal and microwave soil moisture retrievals, Adv. Water Resour., 33, 201-214, 2010.

Liang, X., Lettenmaier, D. P., Wood, E. F., and Burges, S. J.: A simple hydrologically based model of land surface water and energy fluxes for GCMs, J. Geophys. Res., 99, 14415-14428, 1994.

Liang, X., Lettenmaier, D. P., and Wood, E. F.: One-dimensional statistical dynamic representation of subgrid spatial variability of precipitation in the two-layer variable infiltration capacity model, J. Geophys. Res., 101, 21403-21422, 1996.

Manfreda, S. and Fiorentino, M.: A stochastic approach for the description of the water balance dynamics in a river basin, Hydrol. Earth Syst. Sci., 12, 1189-1200, doi:10.5194/hess-12-11892008, 2008.

Manfreda, S., McCabe, M., Wood, E. F., Fiorentino, M., and Rodriguez-Iturbe, I.: Spatial Patterns of Soil Moisture from Distributed Modeling, Adv. Water Resour., 30, 2145-2150, 2007.

Manfreda, S., Lacava, T., Onorati, B., Pergola, N., Di Leo, M., Margiotta, M. R., and Tramutoli, V.: On the use of AMSU-based products for the description of soil water content at basin scale, Hydrol. Earth Syst. Sci., 15, 2839-2852, doi:10.5194/hess-152839-2011, 2011.

Matgen, P., Heitz, S., Hasenauer, S., Hissler, C., Brocca, L., Hoffmann, L., Wagner, W., and Savenije, H. H. G.: On the potential of METOP ASCAT-derived soil wetness indices as a new aperture for hydrological monitoring and prediction: a field evaluation over Luxembourg, Hydrol. Process., 26, 2346-2359, 2012 a.

Matgen, P., Fenicia, F., Heitz, S., Plaza, D., de Keyser, R., Pauwels, V. R. N., Wagner, W., and Savenije, H.: Can ASCAT-derived soil wetness indices reduce predictive uncertainty in well-gauged areas? A comparison with in situ observed soil moisture in an assimilation application, Advances in Water Resources, 44, 49-65, doi:10.1016/j.advwatres.2012.03.022, 2012b.

Moran, M. S., Peters-Lidard, C. D., Watts, J. M., and McElroy, S.: Estimating soil moisture at the watershed scale with satellitebased radar and land surface models, Can. J. Remote Sens., 30, 805-826, 2004.

Nied, M., Hundecha, Y., and Merz, B.: Flood-initiating catchment conditions: a spatio-temporal analysis of large-scale soil moisture patterns in the Elbe River basin, Hydrol. Earth Syst. Sci. 17, 1401-1414, doi:10.5194/hess-17-1401-2013, 2013.

Ochsner, T., Cosh, M., Cuenca, R., Dorigo, W., Draper, C., Hagimoto, Y., Kerr, Y., Larson, K. M., Njoku, E. G., Small, E. E., and Zreda, M.: The state of the art in large-scale soil moisture monitoring, Soil Sci. Soc. Am. J., 77, 18881919,doi:10.2136/sssaj2013.03.0093, 2013.

Pan, F., Peters-Lidard, C. D., and Sale, M. J.: An analytical method for predicting surface soil moisture from rainfall observations, 
Water Resour. Res., 39, 1314, doi:10.1029/2003WR002142, 2003.

Pellarin, T., Laurent, J. P., Cappelaere, B., Decharme B., Descroix, L., and Ramier, D.: Hydrological modelling and associated microwave emission of a semi-arid region in South-western Niger, J. Hydrol., 375, 262-272, 2009a.

Pellarin, T., Tran, T., Cohard, J.-M., Galle, S., Laurent, J.-P., de Rosnay, P., and Vischel, T.: Soil moisture mapping over West Africa with a 30-min temporal resolution using AMSR-E observations and a satellite-based rainfall product, Hydrol. Earth Syst. Sci., 13, 1887-1896, doi:10.5194/hess-13-1887-2009, 2009 b.

Porporato, A., Daly, E., and Rodriguez-Iturbe, I.: Soil water balance and ecosystem response to climate change, Am. Nat., 164, 625632, 2004.

Puma, M. J., Celia, M. A., Rodriguez-Iturbe, I., and Guswa, A. J.: Functional relationship to describe temporal statistics of soil moisture averaged over different depths, Adv. Water Resour., 28, 553-566, 2005.

Ragab, R.: Towards a continuous operational system to estimate the root zone soil moisture from intermittent remotely sensed surface moisture, J. Hydrol., 173, 1-25, 1995.

Rawls, W. J. and Brakensiek D. L.: Estimation of soil water retention and hydraulic properties, in: Unsaturated Flow in Hydrologic Modeling, Kluwer Acad., Dordrecht, Netherlands, 275300, 1989.

Rawls, W. J., Ahuja, L. R., Brakensiak, D. L., and Shirmohammadi, A.: Infiltration and soil water movement, in: Handbook of Hydrology, edited by: Maidment, D. R., 5.1-5.51, 1993.

Redelsperger, J.-L., Thorncroft, C. D., Diedhiou, A., Lebel, T., Parker, D., and Polcher, J.: African Monsoon Multidisciplinary Analysis: An International Research Project and Field Campaign, B. Am. Meteorol. Soc., 87, 1739-1746, 2006.

Reichle, R., McLaughlin, D., and Entekhabi, D.: Hydrologic data assimilation with the ensemble kalman filter, Mon. Weather Rev., 130, 103-114, 2002.
Reichle, R., Koster, R., Dong, J., and Berg, A.: Global soil moisture from satellite observations, land surface models, and ground data: implications for data assimilation, J. Hydrometeorol., 5, 430-442, 2004.

Rodriguez-Iturbe, I., Isham, V., Cox, D. R., Manfreda, S., and Porporato, A.: Space-time modeling of soil moisture: stochastic rainfall forcing with heterogeneous vegetation, Water Resour. Res., 42, W06D05, doi:10.1029/2005WR004497, 2006.

Sabater, J. M., Jarlan, L., Calvet, J. C., Bouyssel, F., and De Rosnay, P.: From Near-Surface to Root-Zone Soil Moisture Using Different Assimilation Techniques, J. Hydrometeorol., 8, 194-206, 2007.

Schaefer, G. L., Cosh, M. H., and Jackson, T. J.: The USDA Natural Resources Conservation Service Soil Climate Analysis Network (SCAN), J. Atmos. Ocean. Tech., 24, 2073-2077, 2007.

Scipal, K., Drusch, M., and Wagner, W.: Assimilation of a ERS scatterometer derived soil moisture index in the ECMWF numerical weather prediction system, Adv. Water Resour., 31, 1101-1112, 2008.

Seneviratne, S. I., Corti, T., Davin, E. L., Hirschi, M., Jaeger, E. B., Lehner, I., Orlowsky, B., and Teuling, A. J.: Investigating soil moisture-climate interactions in a changing climate: A review, Earth-Sci. Rev., 99, 125-161, 2010.

Wagner, W., Lemoine, G., and Rott, H.: A method for estimating soil moisture from ERS scatterometer and soil data, Remote Sens. Environ., 70, 191-207, 1999.

Walker, J. P. and Houser, P. R.: Requirements of a global nearsurface soil moisture satellite mission: accuracy, repeat time, and spatial resolution, Adv. Water Resour., 27, 785-801, 2004.

Wood, E. F., Lettenmaier, D. P., Liang, X., Nijssen, B., and Wetzel, S. W.: Hydrological modeling of continental-scale basins, Annu. Rev. Earth Pl. Sc., 25, 279-300, 1997.

Ye, M., Meyer, P. D., and Neuman S. P.: On model selection criteria in multimodel analysis, Water Resour. Res., 44, W03428, doi:10.1029/2008WR006803, 2008. 